\title{
Positioning a Bank Service in Nigeria: A Conceptual Framework
}

\author{
OLALEKAN ASIKHIA \\ Lecturer, Department of Business Studies \\ College of Business and Social Sciences, Covenant University, Ota, Canaan land \\ Km.10, Idiroko, P.M.B.1023, Ota, Ogun state, Nigeria \\ Tel: 234-0803-3951-474Ｅ-mail: lekanasikhia@yahoo.com
}

\begin{abstract}
The study looks at positioning of bank service in a competitive environment like Nigeria. Positioning was examined from the various definitions in the literature and the major components and strategies of positioning were discussed. The bank service in Nigeria was seen to be best positioned through non-functional and functional benefits. The non-functional benefits involve the bank's corporate identity and brand image, this were seen to be well suited for old banks with high public acceptance, and positioning through functional benefits, which involve developing new attributes for the product or altering the old attributes of the product was found to be well suited for both old and new banks, and a framework for this was also developed.
\end{abstract}

Keywords: Positioning, Bank service, Banks, Conceptual framework, Nigeria

\section{Introduction}

A bank service helps to distribute resources of a nation from a high concentrated area to a low concentrated area, to facilitate national growth and development. But numerous external forces shape the market of bank service (Zeithaml, Bitner, and Gremler, 2009)). The service is affected by economic, technological, demographic, socio-cultural, political and legal factors.

The level of prosperity, changing levels of disposal income, inflation rates, stock market performance, the rate of unemployment, shortages of raw material - all these affect the packaging and delivery of a bank service. The combination of interest rates, consumers' short term and long-term expectations concerning its direction as well as the general level of competition create marketing challenges for the bank service.

Education and occupation have a definite relationship with social class and consumer banking behavior and government exerts some amount of influence on bank service in order to protect consumers, the economy and other related entities through different regulatory frameworks. All of these put together affect the bank service. Most of prudential regulation of banking was predominant in United States in the mid - 70s emanating as a result of the single-office banking system and traumatic experience of bank failures, particularly during the great depression of the 1980s. And when addressing the Lombard Association in April 1987 on the Central banking origins of the bank's supervision, the deputy governor of the Bank of England said he never remembered hearing that word 'supervision' used in the bank before 1974. The traumatic experiences of the fringe banking crises and bank failures of 1973/74 in the United Kingdom and the similar crisis and failure in the highly regulated banking system of Europe and America further enhance bank regulation all over the world, thus banks regulation becomes a prominent factor to envisaged and build into banking operations in order to survive. Nigeria is not different, the bank failure of 1990 - 1994 and recapitalization policy of December, 2005 and the toxic loans saga of 2009 have affected the practice of banking.

Adding to this is the fact that banks have gradually realized that due to the presence of globalization and changing technology there is dire need to overhaul their payment and service delivery systems and operations so as to prosper in the new millennium.

Based on the foregoing, it becomes paramount to advance a conceptual framework that would serve as a guide to position the bank service in this turbulent environment of operations.

\section{Literature Review}

\section{Positioning: Definitional Approach}

Kotler (2003) defines positioning as the act of designing a firm's offering and image to occupy a distinctive place in the mind of the target market with concomitant effect of creating a customer-focused value proposition that would facilitate patronage. 
Ries and Trout (1986) see positioning as a collection of creative activities that manipulates the consumers' mind in favour of the brand. They emphasize that positioning starts with a product and ends up creating a space and occupying it in the consumers' minds. They argue that a well-known brand only holds a distinctive position in consumer's mind which may be difficult for the competitors to claim, and that this position would only be maintained with well-articulated strategies concerning product, price, place, and promotion.

Treacy and Wiersema (1994) view positioning as a collection of activities that instills value disciplines such as product leadership, operational excellence or customer-intimacy. This is based on the notion that in every market, there is a mix of three types of customers; some that prefer firm that is technologically inclined (product leadership); others that favour a highly reliable performance (operational excellence) and still, others want high responsiveness in meeting their individual needs (customer intimacy). They argue that no firm is best in any two of these ways as each value disciplines requires different managerial mind-sets and investments that often conflict.

Treacy and Wiersema (1994) thus propose that for a business to be successful in positioning its brand there are four major things it must do in this light, first it must become best at one of the three value disciplines, second, it must also achieve adequate performance level in the other two disciplines, third, it must keep improving its superior position in the chosen discipline so as not to lose its position to competing firms and finally, it must not lose sight of the relevance of the other two disciplines as competing firms raise customers' expectations.

Sengupta (1997) sees positioning as an act of identifying a vacant space in the consumers' mind space and occupying it for periods that varies according to the quality and quantity of marketing efforts behind the brand. He views it as a deliberate attempt to create a perception for a brand in the prospects' mind so that it stands apart from competing brands and approximates much more closely to what the consumers want. It is a matter of finding a strong position in that mind and sit on it, which means the same brand, in the same pack, with the same formulations can seek different positions in the consumer's mind space. He argues that positioning is less of what we do to the product and more of what we do to the customer's perception of the product. He further emphasizes that positioning is thus the fountain head decision, from which flows all other marketing and advertising decisions and that it provides the direction and thrust to marketing and advertising planning and also fuse them and the marketing mix into a cohesive whole. He finally submits that the position of a brand is its perception among target consumers based on its functional attributes and benefits, as well as on the non-functional or emotional associations it has acquired from its advertising. The colouration of these different perceptions by consumers' own attitudes, beliefs and experience, make different consumers segments to perceive the brand differently, and secondly the brand's position is perceived in relation to competitive brands. This position concurs with the opinions of Perreault Jr. et al (2009) and Kerin et al (2010).

However, Etzel, Walker and Stanton (2007) see it as fitting the product to the segment where product performances and appeals most correspond. It infers that there is a point where the appeal of a product corresponds with its performance. That is, the point where the quality that makes the product attractive or interesting must equate to its performance, such that, the customers are not disappointed, and thus fulfilling the unspoken promises made to the customers. Etzel et al (2007) recognizes this point as the positioning of the brand. This sounds vague and divergent from earlier thoughts of image creation and mind space as postulated by Kolter (2003), Ries and Trout (1982) and Segupta (1997) but tend to align with Treacy and Wiersena (1994)'s idea of product leadership.

Smith and Lusch (1976) define positioning as a brand's objective or (functional) attributes in relation to other brands; it is a characteristic of a physical product and its functional features. They see 'position' as brand's subjective or perceived image which belongs not to the product, but rather, it is a mental picture, which could differ from the true physical picture of the brand. The definition emphasizes attributes analysis and estimation that positions the brand in the mind of the consumers, which makes the definition to align with the views of Kotler (2003) and Segupta (1997) but specific issues pertaining to product leadership, operational excellence or customer intimacy are not mentioned but may be inferred.

Rosser Reeves as cited by Sacco (1986) sees positioning as the art of selecting, out of a number of unique selling propositions, the one which will get you maximum sales. This definition looks at positioning superficially, it lacks the depth that the earlier definitions carry, because positioning is more than framing a set of words, the definition also plays down on the opinion of Crawford (1987) who believe that positioning is meant to drive the entire marketing programme of the organization, which aligns with Aaker (1984)'s view that product positioning is so central and critical that it should be considered at the level of a mission statement because it comes to represent the essence of a business. 
From the foregoing, it is obvious that what 'positioning' represents seems to be ambiguous as the meaning varies from one researcher to another. However, positioning from the literature reviewed could thus be said to be, the perception of a brand that the consumers hold which makes it to occupy a space in the mind of the consumer as a brand leader, or operationally excellent brand, or customer intimated brand.

\section{Components of Positioning}

Sengupta (1997) advances four components of positioning, which are product class, consumer segmentation, consumer perception and brand benefits. The product class denotes the set of products and brands which are perceived as substitute to satisfy some specific needs, it helps to identify the practical space in the mind of the consumer to occupy and the brands that are occupying such space presently. The particular brand that is occupying such space must be a close substitute of the intending brand for it to fit in to the space thus knowing the space gives the picture of the structure of the market.

The choice of product class could be used to secure competitive advantage for the brand through identifying the profile of the consumers and their needs, and directing all marketing efforts like promotional and media efforts toward these sets of consumers patronizing the brand in this product class. So, consumer segmentation is another component of positioning, identifying the consumers' characteristics, needs and expectations often makes one to know that segments do exist amidst consumers. Most leading brands with very large market shares often position themselves across several segments (Kerin, Hartley, and Rudelius, 2010). Sengupta (1997) says there is inseparable relationship between the position of a brand and its target segment. The more similar a brand is to other brands the more difficult it is to have a definite and distinct positioning, that is, there is need to be unique amongst the similar, thus carving out a niche for the brand.

The third component of positioning deals with the need to see where the brand is positioned in the mind of his prospects in relation to other brands, this is done with two-dimensional space called perceptual mapping. It helps to make positioning as a concept to be operational, the judgments of managers, sales staff or channel members are used to plot the brand position in the perceptual space of the consumers, and the customers may also be asked to rate the brand along attributes or benefits or they may be asked to judge by pairs, how similar or dissimilar the brands are (Urban, Hauser and Dholakia, 1987). So, the perceptual mapping gives a picture of the level of similarity and competitiveness among different brands by using measure of preferences between brands and ratings of brands on various attributes.

The final component of positioning is brand attributes and benefits, for the brand to occupy a space in the consumer's perceptual map; it must be in consumer's frame of reference, which requires that the brand attributes (which are the manufacturer's claim) be translated into consumer benefits. For a brand to be positioned with reference to an attribute, such attribute must be reinterpreted as measuring consumer benefit. So, it is important to search for vacant positions in the market with reference to preferred benefits and the preferred importance of such benefits.

The customer often evaluate the brand (both physical and emotional benefits) to know where it fits into their framework of needs and wants, since 'position' denotes the consumer's perceived distance from one another. When the perception of the brand has stimulated the consumer's interest, then the consumer gives it a space in her mind, then relates it with other competing brands, which may also have earned positions in her mind, the consumer then patronizes the brand, if he finds it to be better than others..

Consumers are able to form a mental picture of a given brand based on its functional attributes, performance and advertising because brand position is supported by its attribute and these attributes must be communicated in a special way, e.g. consumers may be made to perceive the product in different way without doing anything to the product by emphasizing one attribute of the brand over another because there is a link between the position of the brand as perceived by the target consumer and some of the brand's functional and non-functional attributes.

Cravens and Piercy (2009) say that positioning strategy of looking at the world of the product through the consumers eyes and locating a promising vacant position in their minds must come first while articulation of the fitting attributes of the product must come next at the planning stage.

\section{Positioning Strategies}

Positioning strategies are needed to locate a niche in the market where the brand is perceived by the target audience as unique, which would invariably help to achieve competitive advantage.

The different types of positioning are thus stated:

\section{(i). Positioning by Corporate Identity}


This is only relevant where the organization has become a household name, such corporate identity can be used to position the product for acceptability and patronage.

\section{(ii). Positioning by Brand Endorsement}

This is a positioning used in growing a brand out of an existing successful brand, thus helping the new brand to key into the perceptual space of the old brand in the mind of the consumers.

\section{(iii). Macro-Positioning}

It relates to positioning the brand in a less-crowded category provided the attributes of the product can match consumer expectations from that category. This will make the brand to be seen differently. However, suitable modifications in the brand functional features and other elements may be needed to communicate it to the new market because new distribution, pricing, as well as competition may need to be defined.

\section{(iv). Benefit - Related Positioning}

This is a positioning of a brand through a unique combination of benefits, which may need to flow from feature or attribute, because consumers buy benefits not features. Attribute is important to consumers only when it leads to the special benefits, which the consumers seek, when the attribute provides the convincing reason of how the brand delivers the benefits. Atimes when the functional attributal differences amongst brands are obvious, marketer could use unique selling proposition to communicate this to the target market, but where the attributes of brands in the same product class are the same, the only option left for the marketer is to position such brand through benefit positioning, so that the position, which the consumer gives it in the her mind represents her perception of the brand in terms of the tangible or functional benefit and non-functional or emotional benefits.

\section{(v). Positioning by Usage Occasion and Time of Use}

It is important to pre-empt a particular usage, this is a strategy of creating and dominating a specific usage occasion. This is a more specific positioning strategy of having to identify a usage situation and sitting on it. It helps to attract adequate number of consumers, when a brand wishes to expand its market by creating and occupying other usage positions. However, competitive credibility is important if the usage of a brand has to be expanded, it must be credible enough in the intended segment to deliver the promise before it can succeed.

\section{(vi). Price-Quality Positioning}

Consumers have different expectations for quality at a particular level of price at different levels of socioeconomic status; this offers a greater opportunity for marketer to position their product through price-quality positioning. Varying levels of price-quality relationship of products often attract different segments of consumers. However, when the price of a brand goes up mainly because of cost and the quality remains the same, marketer often try to use Advertising and Repackaging to create a "quality" difference to shore up the quality of the brand against the price, this may create a credibility gap that may negatively affect the brand's patronage. But the right thing is that consumers get satisfied when there is actual value for money, and Advertising and Repackaging of such brand give a subjective added value that will go further to create an image that places it above its perceived rank on the price-quality ladder. So it is important to first and foremost ensure that price-quality ratio is balance, an imbalance in this ratio must be corrected by either increasing the benefits of the product through quality enhancement or increase price to meet with quality offered because usage for a 'value' brand can be enhanced to the level where it reinforces the users purchase decision but not to the point of the where it stretches the credibility of the brand.

\section{(vii). Positioning by Target Segment}

It involves positioning the brand to a set of consumers with similar needs and expectations from the brand and such consumers have similar characteristics in Demography (i.e. Age, income, sex, occupation, education, geographic location, etc.), Behaviour (e.g. volume of usage) Benefit or satisfaction desired, and Psychography (e.g. personality, lifestyle, social class, etc.). When a brand is positioned through any of the above, the segment tend to be strongly identified with it and thus give a distinct and unique identity to the brand.

For behavioural positioning particularly for heavy users of the brand, it gives that advantage of allowing small group of people to represent large percentage of the brand's patronage, that is; though the number of users is few but the volume of brands sold is high. It makes a lot of sense to position for heavy users when it is needful for resources to be economized.

The marketer can also find out the consumers that are linked together by benefit or satisfaction they derive from the brand, he then develops or modifies the brand and positions it to fit into this set of definite needs. 


\section{(viii). Positioning by Unique Attribute and Competitor}

It is important atimes to position the brand by unique attribute of feature that makes it superior to competition. This attribute must be able to translate into benefit to give it a differential advantage at the market place.

And the brand could also be positioned against the competing brands. This is an offensive strategy that involves comparing the brand with other brands and showing why the brand should be preferred.

\section{(ix). Positioning with Non-functional Values}

Products are bought not only for their physical benefits but also for their symbolic or non-functional ones. Atimes customers are ready to pay twice for the symbolic meaning of a brand than for the physical attribute. This work for products that have conspicuous consumption as well as product whose identity is known only to the user. Others will see the result from the use of the product but they may not know until they ask of the name - this also has an implication for word - of - mouth publicity effect. The symbolic meaning that a brand commands is often called the brand image.

The consumption of a brand may be more important to the individual consumer than the functional benefits provided by the brand; actually advertising communicates the symbolic and indirect meanings that the brand represents. And the brand name is always a complex symbol that represents a variety of ideas and attributes, and the consumer buys when the symbolism fits. And the brand takes it up from there by creating strong bonding with emotions between itself and the consumer. The importance of symbolism in brand choice goes up when 'rationality' of the buying decision goes down (Sengupta, 1997). Brand symbolism has been established to have conceptual strength and operational utility (Arens, Weigold and Arens, 2010).

Some researchers have also shown a high congruency between owners' perception of himself and the brand products he buys (Budwell, 1968; Belch and Belch, 2009; Arens et al, 2010)

The self-Image of the consumer is the combination of its person's basic physical and emotional characteristics of the image of his 'real' self and of his 'ideal' self (i.e. the self he would like to be, this includes his aspirations). It is thus rational to feel that the consumer would buy products consistent with self-Image, and avoid products inconsistent with self-image, and engage in more transactions of products that facilitate his self-image. Therefore, in positioning a brand with its symbolic meaning, such symbolism must support the self-concept of the consumer. In many markets there are no real difference among the competitors, the major difference is in the degree of emotional attachments of the customers, this explains why people prefer a particular brand to another even though there is no physical difference between them. However, though this is important but this non-functional attributes must be adequately blended with the physical and functional values to form an integrated brand personality that can command patronage.

\section{Materials and Methods}

Positioning components and strategies as well as bank service in Nigeria were investigated. Also an investigation was carried out on how the bank service could be positioned as a competitive advantage in a turbulent business environment like Nigeria through a thorough examination of the inherent features of each of the bank products. And a conceptual framework for this was sought.

\section{Result and Discussion}

\section{The Bank Service in Nigeria}

Banks are financial institutions that accept deposits and channel them into lending activities. Banks provide financial services that are collection of deposits and lending of such deposits to others that may be in need of them at a price. The bank service thrives on the difference between interest paid on all deposits, which ranges from savings, current to fixed deposits, and the interest received from these deposits when lend out to borrowers. So the bank service is a dichotomous service of two types customers i.e. the depositor and the borrower, as shown in figure 1. There will be no service to render by the banks if they cannot attract depositors whose money they will use to establish their relationship with the borrower apart from buying and selling of foreign currencies.

\section{Figure 1 here}

The attraction of these two types of customers are essential for the survival of the bank because if the depositors are attracted and no one is borrowing the money, there would be excess/idle funds in the bank whose cost will be on the bank, the attraction of the two types of customers is imperative for banks survival.

Three major accounts could be said to be existing in every bank, these are savings, current and deposits accounts. These three accounts differ on the basis of requirements, benefits, level of risk and maximum balance. These 
four variables also determine the proportion of the products that exist in every bank. The savings account has a low level of requirement (for example with any form of identification and a definite place of residence one can open the account); the interest paid on the savings account is the lowest amongst all deposits in most countries); It has high level of risk to the to the bank; (advent of electronic banking has revealed a high level of fraud being perpetrated by holders of this accounts, as it has been discovered that most of the forms of identification used to open such accounts are fake), maximum balance is restricted, (to mitigate this level of risk, banks have set a maximum balance that must be in such account, this is done to reduce the level of risk that is borne by the banks in event of fraud.

The saving account differs in requirement and benefits depending on the type. The average interest rate on it ranges from $1-3 \%$ per annum. The higher the interest rate paid to customer the higher the requirements; examples of such requirements are; compulsory savings overtime, little form of insurance, no withdrawal except by termination, where withdrawal are allowed it must not be more than three times in a year or the customers forfeits the interest.

\section{Table 1 here}

For current account the requirement for opening the account is high because of the different demands placed on the customers e.g. the customer must be a working class whose salary must be paid into the account i.e. salary current account and all identifications to prove this are required, or customer must have a company that he intends all financial transactions pass through i.e. corporate account/Enterprise account, or a customer wishes that all his financial benefits should be deposited and allocated appropriately after death, i.e. trustee account. All these accounts have high benefits relative to costs, low risk to the bank and unrestricted value to depositors. And the domiciliary account is one that the customer makes deposits and withdrawal of foreign currency depending on the type of the currency e.g. Dollar, Pounds, Euros, etc.

The deposits accounts' requirements are generally low; the period of deposits in most cases distinguishes the different types. It is fixed deposit if it is deposited for a period of one month or less, it is called call deposit when the period is more than one month but less than 1year, it is called a bankers' acceptance when bigger value is involved for a longer time. The benefits enjoyed differ with time and value of the money deposited, for example while with-holding tax and VAT is charged on the fixed deposit, it is not charged on the Bankers' acceptance. The level of risk is low and the maximum deposit is not restrictive. However, the risk of collecting deposits may be high when the bank does not have borrowers to use such monies, because while the bank may be required to pay the customer who deposited the money an interest of about 5 to $8 \%$ per annum, when no customer comes forth to borrow such money the only option for the bank is to deposit it with the Central bank of Nigeria that will pay an interest of only $1 \%$ per annum. This is a loss of about 4 to 7 percent to the bank. This further lay credence to the importance of the borrowing customers. But when there is a borrowing customer, the bank lends out such money at the rate of 20 percent per annum or more, thus making a gain of $17-20$ percent on any money deposited.

\section{Positioning a Bank Service in Nigeria: A Conceptual Framework}

Service as a form of offering has unique characteristics such as intangibility, inseparability, variability, and perishability (Perreault Jr., Cannon and McCarthy, 2010). The service industry is a complex, dynamic and competitive environment. Banks in Nigeria witness increased competition that makes it necessary for a bank to position her service effectively to gain competitive advantage.

Positioning by corporate identity is possible for banks that have acquired high market acceptance over the years; most banks that are big and reliable, especially banks that have sufficiently survived the era of Nigerian banks failures of 1990 - 1994, the recapitalization era of December, 2005 and the recent toxic loan saga of 2009. Amongst this set, some of the banks cannot still position their service in this manner because their market acceptance has decreased over the years even though they have not totally failed. So, very few banks can afford to position their service in this category.

Positioning by Brand endorsement can also be done by banks that have had a successful offering or brands, using the new brand to occupy the perceptual space of the old brand in the mind of the consumers will not be difficult.

\section{Figure 2 here}

Macro positioning of bank service requires an in-depth research of the needs of the customers, then these specific needs are either encapsulated into a new product offering or the old product is modified to fit into it. For example, the savings account could be modified to specifically serve the retirees, or students or teachers who have specific needs that could be incorporated into the offering. Such modification or new product must be well 
communicated to the target audience using the appropriate medium and all organizational framework that will support the implementation must be put in place aside the need to modify other Ps of marketing that are supposed to provide the necessary complements.

The current and the fixed deposits of banks could be best positioned as Benefit related positioning where more benefits would be attached to these accounts because these two accounts give the banks separate advantages, while the bank benefits from the charges on current account, they pay for the funds of the fixed deposits through interest but such deposits are used as loanable funds to borrowers who pay higher interest. It is important therefore for every bank to distinguish these services from competitors by attaching additional benefits to it, which may alter their attributes, but allows it to be positioned in a new perpetual space in the customers' mind. For example, the current account holder could enjoy more ease of bank transfer, notice of deposits and withdrawals, greater representation of his bank in business transaction, etc., while the fixed depositor may enjoy facilities that would lessen the effect of his money being fixed e.g. unfix the fixed by issuance of cheque books to such persons who fix with the intention that they may require their monies before maturity, thus allowing for an arrangement that makes them to withdraw without totally losing their "fixed" status. Cost of this service will be deducted from the naira value of the interest rate at the end of deposit period. This service relaxes the fixed nature of the fixed deposit account without the bank incurring any loss.

Bank service could also be positioned by usage occasion and time of use through identification of a particular target audience's needs that is attached with occasion or time e.g. for students during collection of University entry forms, West African Examination Council's forms, etc, payment of school fees etc, special services during these time would enhance the patronage of such banks apart from being an avenue of establishing new relationships. As shown in figure 1, the impact of these positioning is often reflected in increase in patronage or market share.

\section{Conclusion}

Positioning denotes identifying a vacant space in the consumers' mind space and occupying it. The major components of positioning are product class, consumer segmentation, consumer perception and brand benefits. It is noted that bank service in Nigeria could be positioned through non-functional and functional means. The non-functional means involves making use of the corporate identity and the brand image of the bank where such bank has had high market acceptance, and functional positioning involves making use of the benefits derivable from the product attributes, which may be new attributes or modified attributes and when the product is rightly positioned in the right context it would lead to increase in patronage and enhanced market share for the bank.

\section{References}

Aaker, David. (1984). Strategic Market Management. New York: Wiley.

Arens, William, Weigold, Michael and Arens, Christian. (2010). Contemporary Advertising. New York: McGraw Hill.

Belch, George and Belch, Michael. (2009). Advertising and Promotion: An Integrated Marketing Communications perspective. New York: McGraw Hill.

Cravens, David and Piercy, Nigel. (2009). Strategic Marketing. New York: McGraw Hill.

Crawford, Merle. (1987). New Products Management. New York: Irvin.

Etzel, Michael, Walker, Bruce and Stanton, William. (2007). Marketing. New York: McGrawHill.

Kerin, Roger., Hartley, Steve and Rudelius, William. (2010). Marketing. New York: McGraw Hill.

Kotler, Philip. (2003). Marketing Management. New Jersey. Prentice Hall.

Perreault Jr. William, Cannon, Joseph and McCarthy, Jerome. (2009). Basic Marketing. New York: McGraw Hill.

Ries, Al and Trout, Jack. (1986). Positioning: The Battle of Your Mind. New York: McGraw Hill.

Sacco, Joe. (1986). 'Roser Reeve’ lost chapter. Adverting Age, October 17.

Sengupta, Subroto. (1997). Brand Positioning. New Delhi: McGraw Hill.

Smith, Robert and Lusch, Robert. (1976). How advertising can position a brand. Journal of Advertising Research, 16(1), February.

Treacy, Michael and Wiersema, Fred. (1994) The disciplines of market leaders. Reading, M.A.: Addison-Wesley. 
Urban, Glen, Hauser, John, and Dholakia, Nikhilesh. (1987). Essentials of New Product Management. New Jersey: Prentice-Hall.

Zeithaml, Valerie, Bitner, Mary Jo., and Gremler, Dwayne. (2009). Services Marketing: Integrating Customer focus across the firm. New York: McGraw Hill.

Table 1. Analysis of Bank Product

\begin{tabular}{|l|c|c|c|c|}
\hline \multicolumn{1}{|c|}{ Variable } & $\begin{array}{c}\text { Requirements for } \\
\text { Opening Account }\end{array}$ & $\begin{array}{c}\text { Benefits enjoyed } \\
\text { Relative to Cost. }\end{array}$ & $\begin{array}{c}\text { Level of Risk to } \\
\text { Banks }\end{array}$ & $\begin{array}{c}\text { Maximum } \\
\text { Balance }\end{array}$ \\
\hline Savings Account & Low & Low & High & Low \\
\hline Current Account & High & High & Low & High \\
\hline Deposit Account & Low & High & Low & High \\
\hline
\end{tabular}

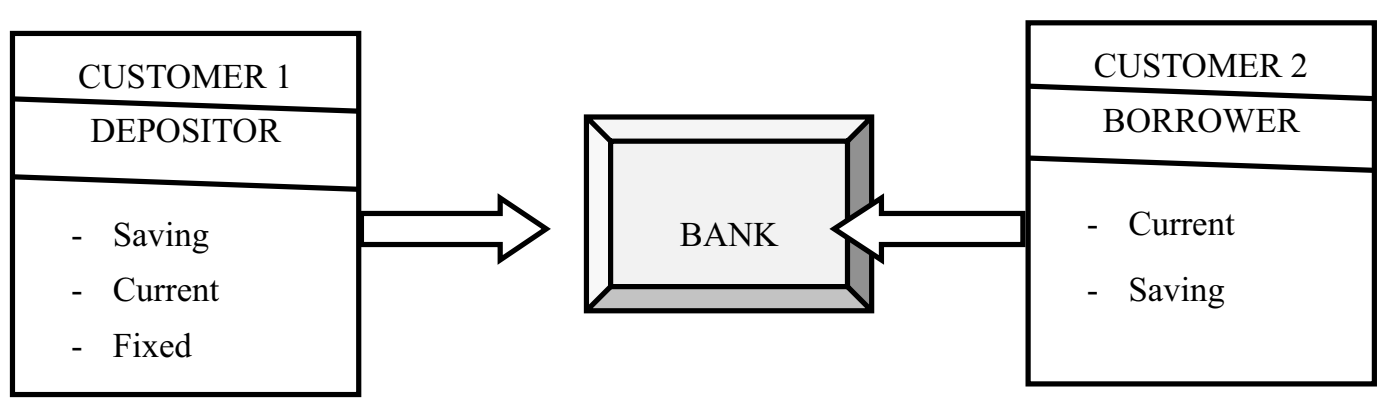

NON-FUNCTIONA

Figure 1. Bank Marketing Process

$\mathbf{L}$

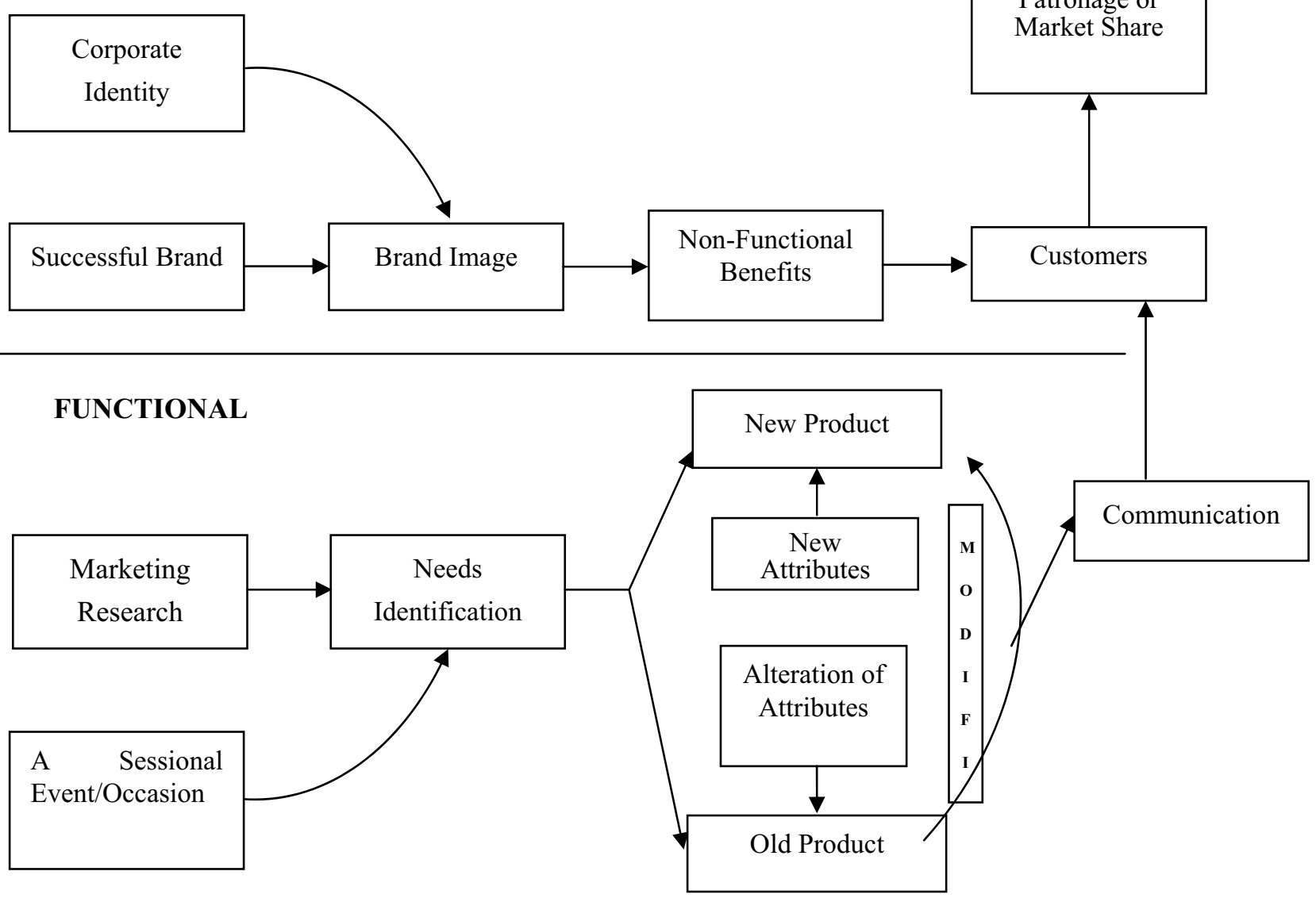

Fig. 2. Conceptual frame work of positioning a bank Service 